\title{
PROPUESTA DE SEGUIMIENTO DE LAS SENTENCIAS DE PRIMERA INSTANCIA EN MATERIA FAMILIAR: PROBLEMÁTICAS Y RETOS
}

\author{
PROPOSAL FOR FOLLOW-UP OF FIRST INSTANCE JUDGMENTS IN FAMILY \\ MATTERS: PROBLEMS AND CHALLENGES
}

\author{
Priscila Pérez-Méndez ${ }^{1 *}$ (D). \\ 1. Escuela Judicial del Estado de Tabasco, México. priscila-mendez1@hotmail.com \\ * Autor de correspondencia: Priscila Pérez-Méndez, correo electrónico: priscila-mendez1@hotmail.com
}

\section{RESUMEN}

En este artículo se analiza las problemáticas que se presentan al momento de pretender ejecutar una resolución judicial, dictada por un Juez Familiar de Primera Instancia o bien un convenio judicial con autoridad de cosa juzgada. El Código de Procedimientos Civiles en vigor del Estado de Tabasco, en sus artículos 383 y 385 establecen las formas de "EJECUCIÓN FORZOSA" y "EJECUCIÓN DIRECTA". De los que se interpreta que la ejecución directa se actualiza cuando no tenga que intervenir necesariamente el adversario de la parte que pida la ejecución; interpretado a contrario sensu, la ejecución forzosa tiene lugar cuando existe oposición por la parte contraria. Sin embargo, no se especifica el trámite a seguir, sobre todo cuando existe una parte que se opone a la ejecución; por lo que, ante la falta de disposición expresa la ejecución se sigue a través de una demanda incidental, en la que las partes tienen que someterse nuevamente a un juicio, ofrecer pruebas, y desahogarlas, hasta la emisión de una sentencia en el que la autoridad nuevamente ordene su cumplimiento y que resulta muchas veces tardado. Sucede similar cuando en una resolución de manera oficiosa se ordenan terapias psicológicas a las partes, y una vez que se eleva a categoría de cosa juzgada, se ordena el archivo del procedimiento al haber concluido; sin darle seguimiento a las terapias psicológicas. De ahí la importancia de que exista un procedimiento de ejecución en materia familiar, así como una autoridad que se encargue del procedimiento como un juzgado de ejecución.

Palabras clave: Resoluciones judiciales; ejecución; procedimiento.

Cómo citar:

Pérez-Méndez, Priscila. (2021). Propuesta de seguimiento de las sentencias de primera instancia en materia familiar: problemáticas y retos. Revista de Investigaciones Universidad del Quindio, 33(S2), 118-124. https://doi.org/10.33975/riuq.vol33nS2.625 


\begin{abstract}
This article analyzes the problems that arise when trying to execute a judicial decision, issued by a Family Judge of First Instance or a judicial agreement with res judicata authority. The Civil Procedures Code in force in the State of Tabasco, in its articles 383 and 385 establish the forms of "FORCED EXECUTION" and "DIRECT EXECUTION". Of which it is interpreted that direct execution is updated when the adversary of the party requesting execution does not necessarily have to intervene; interpreted a contrary sensu, the execution takes place when there is opposition by the opposing party. However, the procedure to be followed is not specified, especially when there is a party that opposes the execution; Therefore, in the absence of an express provision, the execution is followed through an incidental claim, in which the parties have to again submit to a trial, offer evidence, and release it, until the issuance of a judgment in which the authority again orders its fulfillment and that it is many times delayed. It is similar when in an informal resolution psychological therapies are ordered to the parties, and once it is raised to the category of res judicata, the filing of the procedure is ordered when it has been concluded; without following up on psychological therapies. Hence the importance of having an enforcement procedure in family matters, as well as an authority in charge of the procedure such as an enforcement court.
\end{abstract}

Key words: Court decisions; enforcement; procedure.

\title{
INTRODUCCIÓN
}

Mediante una resolución o convenio judicial, se pone fin a una controversia surgida entre particulares. Así, el proceso de ejecución inicia con el ejercicio del derecho consignado en una resolución jurisdiccional. Su naturaleza jurídica, es el cumplimiento de la obligación consignada de una sentencia o convenio, dado que en la sentencia se consigna la satisfacción del interés de una de las partes (o de ambas) y la insatisfacción de tal interés se genera por el no cumplimiento en forma voluntaria del obligado, generando así el proceso de ejecución (Hutchinson, 2004).

Con base a la estadística de los juzgados familiares de primera instancia con sede en esta Ciudad de Villahermosa, Tabasco, existe un creciente número de resoluciones judiciales desobedecidas y los recursos al alcance de las partes para ejecutarlas, se vuelven complicados ante la falta de un procedimiento para su ejecución, y una autoridad que se encargue de este tipo de procedimientos, lo que provoca que el trámite para la ejecución de una resolución de primera instancia, se realice en la vía incidental en la que se admiten pruebas, se desahogan las mismas y para finalizar se emite una resolución, que resulta tardado, muchas veces por la carga de trabajo que tienen los juzgados familiares o por lo contencioso del litigio.

Cuando de manera oficiosa en una resolución judicial dictada por un órgano jurisdiccional (De Silva, 2004), se ordenan por ejemplo terapias psicológicas, a la par que se ordena el archivo definitivo, no se les da un seguimiento de oficio a dichas terapias.

En virtud del derecho que tiene todo gobernado al derecho a la tutela judicial efectiva, que "puede definirse como el derecho público subjetivo que toda persona tiene, dentro de los plazos y términos 
que fijen las leyes, para acceder de manera expedita a tribunales independientes e imparciales, a plantear una pretensión o a defenderse de ella, con el fin de que, a través de un proceso en el que se respeten ciertas formalidades, se decida sobre la pretensión o la defensa y, en su caso, se ejecute esa decisión" (Naime \& Zaragoza, 2019).

Al respecto es importante estudiar la jurisprudencia internacional respecto a la sentencia de familia, por mencionar "Fornerón e hija vs. Argentina" (CIDH, 27/4/2012) "Saleck Bardi vs. España (TEDH, 24-5-2011).

\section{METODOLOGÍA}

Este artículo describe aportaciones al respecto a la ejecución de sentencias en el derecho familiar para ello, se divide en cuatro apartados: en el primero referente al derecho a la tutela judicial efectiva; en el segundo a la jurisprudencia de los Tribunales Internacionales de Derechos Humanos respecto de la eficacia de la sentencia de familia; en el tercero la inexistencia de un procedimiento de ejecución

y la falta de una autoridad que se encargue del procedimiento de ejecución y por último se refiere a las propuestas del tema. La revisión de la literatura se integró con material diverso, entre los que podemos citar: la legislación adjetiva civil en vigor del Estado de Tabasco, estadísticas realizadas en los juzgados familiares de Primera Instancia con sede en la Ciudad de Villahermosa, Tabasco; así como de jurisprudencia de los Tribunales Internacionales de Derechos Humanos. Otorgando una visión integral de los retos que se tienen que superar ante el creciente número de resoluciones judiciales desobedecidas y los recursos al alcance de las partes para ejecutarlas.

\section{RESULTADO}

\section{Tutela judicial efectiva.}

El artículo 17 Constitucional arropa la tutela judicial efectiva (Silva 2020), que puede definirse como el derecho público subjetivo que toda persona tiene, dentro de los plazos y términos que fijen las leyes (Gerónimo et al., 2021), para acceder de manera expedita a tribunales independientes e imparciales, a plantear una pretensión o a defenderse de ella, con el fin de que, a través de un proceso en el que se respeten ciertas formalidades, se decida sobre la pretensión o la defensa y, en su caso, se ejecute esa decisión. De ahí, que la ejecutoriedad de las sentencias tiene aval constitucional, ya que el derecho a la ejecución de las sentencias se encuentra implícito en la tutela judicial efectiva, pues ella no sería efectiva si se limitara al solo acceso a la justicia o culminara con la determinación de los derechos u obligaciones. El juez no solo es el que juzga, sino también el que manda pues es aquél cuyo juicio tiene la eficacia del mandato.

La Suprema Corte de Justicia de la Nación en México se ha pronunciado respecto a la tutela efectiva en su vertiente de recurso efectivo, la cual reitera a los tribunales resolver conforme a derecho sin dilación e interpretación razonada para una buena administración de justicia.

La justicia no sería efectiva si el mandato de la sentencia pudiera no ser cumplido. Hacer ejecutar lo juzgado es una consecuencia del derecho a la tutela judicial efectiva. Por medio del proceso que no tiene por finalidad crear derechos sino tutelarlos, el Estado hace valer el derecho frente a la conducta que está en pugna con él y lo hace no solo a través de la declaración judicial que se expresa en la sentencia, sino fundamentalmente mediante su ejecución. 
Los procesos permiten poner fin al litigio determinando con certeza el derecho, pero con ello no se agota la función jurisdiccional. No se restablece la paz social por el simple hecho de haber reconocido el derecho de una de las partes a determinada prestación si el vencido en el proceso no cumple habrá que obligarlo a cumplir. En otras palabras, si no ejecuta voluntariamente la sentencia habrá lugar a la ejecución forzosa.

\section{Jurisprudencia de los Tribunales Internacionales de Derechos Humanos respecto de la eficacia de la sentencia de familia}

La efectiva tutela de derechos materiales se advierte en la actividad jurisdiccional a través del cabal cumplimiento.

En la jurisprudencia del Tribunal Internacional de Derechos Humanos respecto a la eficacia en las sentencias en su cumplimiento, algunos casos existentes son: "Fornerón e hija vs. Argentina" (CIDH, 27/4/2012) “Saleck Bardi vs. España (TEDH, 24-5-2011), ”Kopf y Liberda vs. Austria” (CEDH, 171-2012), entre otras.

\subsection{Caso Fornerón e hija vs. Argentina}

Este caso atañe a la responsabilidad internacional del Estado derivado de violación al debido proceso en el caso de tenencia de Fornerón respecto a su hija biológica.

La Corte Interamericana de Derechos Humanos consideró al Estado argentino responsable por la violación del artículo 8 (garantías judiciales y derecho a ser juzgado en un plazo razonable) y 25.1 (protección judicial), en relación con los artículos Artículo 1 (obligación de respeto de derechos) 1.1 (no discriminación), 2 (deber de adoptar disposiciones de derecho interno), 19 (derechos del niño), 17.1 (protección integral de la familia) de la Convención Americana de Derechos Humanos.

Referido a lo competente a procedimiento judicial y administrativo en cuanto a protección del menor, casos particulares: guarda y custodia de menor, adopción, debiendo ser un proceso sin burocracia por parte de las autoridades competentes. El acceso y garantía del derecho a la justicia debe anteponer un tiempo razonable.

Plazo razonable La Corte IDH ha determinado algunos elementos respecto a plazo razonable tales como:

a) complejidad del asunto; b) actividad procesal; c) acción y conducta de autoridades judiciales, d) afectación.

La responsabilidad de apremiar el procedimiento recae sobre las autoridades judiciales.

Razonabilidad. Régimen de visitas. Interés superior del niño.

La singularidad del caso señalado, es el tiempo que distaba originaba efectos irreparables.

Conducta de La acción de las autoridades respecto a este caso ha incurrido en que el padre las autoridades judiciales biológico y su hija respecto a visitas no establezcan un vínculo entre ambos, sin duda, una situación trascendente debido a la etapa de desarrollo emocional y psicológico para la vida de la menor.

En el caso señalado el retraso en las decisiones judiciales generó afectaciones significativas, irreversibles e irremediables que impactaron en los derechos de padre e hija. 


\begin{abstract}
A f e c t a c i ó n Para determinar la razonabilidad del plazo también se debe tomar en cuenta la generada a la afectación generada por la duración del procedimiento en la situación jurídica situación jurídica de la persona involucrada considerando, la materia objeto de controversia. El de la persona Tribunal ha establecido que, si el paso del tiempo incide de manera relevante involucrada en el en la situación jurídica del individuo, resultará necesario que el procedimiento proceso avance con mayor diligencia a fin de que el caso se resuelva en un tiempo breve.

Duración proceso

del En el caso de Fornerón el tiempo en guarda judicial y régimen de visitas, excedió el tiempo considerado como plazo razonable.
\end{abstract}

\title{
Fuente: elaboración propia.
}

\subsection{Saleck Bardi vs. España (TEDH, 24-5-2011)}

En el año 2002, Saltana, arriba a España procedente de los campamentos de refugiados saharauis de Tindouf para una estancia de dos meses. A su llegada a España fue albergada en una familia de acogida. Sin embargo, la estancia se prolongó debido a razones médicas. Siendo que la federación solicitó extensión de tiempo al Servicio de Protección de Menores de la Dirección General de Familia del Gobierno de la Región de Murcia, sin obtener contestación.

Pasado dieciséis meses, la Dirección General de Familia fue notificada que la solicitante reclamaba el regreso de su hija a los campamentos de refugiados de Tindouf. El Servicio de Protección inició entonces un procedimiento con el fin de determinar la evolución del estado de salud de la menor.

En el periodo de 2004, el Servicio de protección de menores expuso a la niña en situación de desamparo $\mathrm{y}$, en aplicación del procedimiento de urgencia, sometiéndola a su tutela y decidió ingresarla en la unidad de observación y acogida de un centro para menores "para su traslado a los campamentos de refugiados de Tindouf con su madre". De lo anterior, la familia de acogida impugnó la resolución.

En 2007, el Juzgado señala resuelve otorgando la tutela de la niña a la familia de acogida.

\section{La inexistencia de un procedimiento de ejecución y la falta de una autoridad que se encargue del procedimiento de ejecución}

En relación a la ejecución de las sentencias o convenio judicial elevados a categoría de cosa juzgada, la legislación procesal civil en vigor del Estado de Tabasco, se refiere de manera general tanto en materia civil como familiar a las formas de "EJECUCIÓN FORZOSA" y "EJECUCIÓN DIRECTA", en sus artículos 383 y 385, que copiados textualmente a la letra dicen:

“ARTÍCULO 383.- Procedencia de la ejecución forzosa. La ejecución forzosa tendrá lugar cuando se trate: I.- De sentencias que tengan autoridad de cosa juzgada; II.- De sentencias sin autoridad de cosa juzgada, pero respecto de las cuales proceda, conforme a este Código, la ejecución provisional; III.- De transacciones y convenios celebrados en juicio o en escritura pública, $y$ aprobados judicialmente; IV.- De autos firmes; V.- De laudos arbitrales firmes; VI.- De títulos ejecutivos; y VI.- De sentencias extranjeras cuya validez haya sido declarada por resolución firme conforme a este Código.".

“ARTÍCULO 385.- Ejecución directa. Procederá la ejecución directa en los casos en que la ley o la resolución que se ejecute la determinen y, además, en los siguientes: I.- Cuando se haga 
valer la cosa juzgada; y II.- Cuando se trate de actos que deban cumplirse por terceros o por autoridades, como inscripciones en el Registro Público de la Propiedad o Catastral, cancelaciones o anotaciones en el Registro Civil de sentencias declarativas o constitutivas, y resoluciones que ordenen la admisión de pruebas, práctica de peritajes u otras diligencias en las que no tenga que intervenir necesariamente el adversario de la parte que pida la ejecución. En estos casos, la ejecución directa se llevará a cabo a petición de parte interesada, y tan pronto como la resolución quede en estado de ser ejecutada".

De los que se interpreta que la ejecución directa se actualiza cuando no tenga que intervenir necesariamente el adversario de la parte que pida la ejecución; e interpretado a contrario sensu, tenemos entonces que la ejecución forzosa tiene lugar cuando existe oposición por la parte contraria; sin embargo, no se especifica el trámite a seguir, sobre todo cuando existe una parte que se opone a la ejecución; por lo que, ante la falta de disposición expresa la ejecución se sigue a través de una demanda incidental, en la que las partes tienen que someterse nuevamente a un juicio, ofrecer pruebas, y desahogarlas, hasta la emisión de una sentencia en el que la autoridad nuevamente ordene su cumplimiento y que resulta muchas veces tardado. Lo mismo sucede cuando en una resolución de manera oficiosa se ordenan terapias psicológicas a las partes, y una vez que se eleva a categoría de cosa juzgada, se ordena el archivo del procedimiento al haber concluido; sin darle seguimiento a las terapias psicológicas.

Derivado de ello, la importancia de que exista un procedimiento de ejecución en materia familiar, así como una autoridad que se encargue del procedimiento como sería un juzgado de ejecución, como los hay en materia penal, ante el creciente número de resoluciones judiciales desobedecidas y los recursos al alcance de las partes para ejecutarlas.

Hay que señalar que no se restablece la paz social por el simple hecho de haber reconocido el derecho de una de las partes a determinada prestación si el vencido en el proceso no cumple habrá que obligarlo a cumplir. En otras palabras, si no ejecuta voluntariamente la sentencia habrá lugar a la ejecución forzosa y para ello, es importante contar con los medios necesarios para su ejecución, esto es que exista un procedimiento especial para el trámite de las ejecuciones en materia familiar, de modo que se garantice el derecho a la tutela judicial efectiva. Hacer ejecutar lo juzgado es una consecuencia del derecho a la tutela judicial efectiva.

\section{Propuesta}

Si bien en la legislación procesal civil en vigor del Estado de Tabasco, se encuentran establecidas las disposiciones legales relativas a las formas de ejecución tanto en materia civil como familiar, es menester que, en materia familiar, exista un procedimiento especial para efectos de regular su trámite, ante el creciente número de resoluciones judiciales desobedecidas y los recursos al alcance de las partes para ejecutarlas. De ahí la importancia de que exista un procedimiento de ejecución en materia familiar, así como una autoridad que se encargue del procedimiento como sería un juzgado de ejecución, como los hay en materia penal.

\section{DISCUSIÓN}

Mediante una resolución o convenio judicial, se pone fin a una controversia surgida entre particulares. Así, el proceso de ejecución inicia con el ejercicio del derecho consignado en una resolución 
jurisdiccional. Su naturaleza jurídica, es el cumplimiento de la obligación consignada de una sentencia o convenio, dado que en la sentencia se consigna la satisfacción del interés de una de las partes (o de ambas) y la insatisfacción de tal interés se genera por el no cumplimiento en forma voluntaria del obligado, generando así el proceso de ejecución.

Ante el creciente número de resoluciones judiciales desobedecidas y los recursos al alcance de las partes para ejecutarlas, se vuelven complicados ante la falta de un procedimiento para su ejecución, y una autoridad que se encargue de este tipo de procedimientos, lo que provoca que el trámite para la ejecución de una resolución de primera instancia, se realice en la vía incidental en la que se admiten pruebas, se desahogan las mismas y para finalizar se emite una resolución, que resulta tardado, muchas veces por la carga de trabajo que tienen los juzgados familiares o por lo contencioso del litigio.

De ahí la importancia de que exista un procedimiento de ejecución en materia familiar, así como una autoridad que se encargue del procedimiento como sería un juzgado de ejecución, como los hay en materia penal, ante el creciente número de resoluciones judiciales desobedecidas y los recursos al alcance de las partes para ejecutarlas.

\section{REFERENCIAS}

1. Cámara de Diputados. (1917). Constitución Política de los Estados Unidos Mexicanos. México. Última reforma publicada DOF 11-03-2021.

2. CEDH. (2010). Case of Schalk and Kopf vs. Austria, Merits, 24 jun., Application no 30141/04, 2010.

3. Congreso del Estado de Tabasco. (1997). Código de Procedimientos Civiles en vigor del Estado de Tabasco.

4. Corte Interamericana de Derechos Humanos. (2012). Caso Fornerón e Hija Vs. Argentina. (CIDH, 27/4/2012). Costa Rica.

5. De Silva, Carlos. (2004). El acto jurisdiccional. Isonomía, (21), 157-191.

6. Gerónimo González, Paulino, Silva Hernández, Francisca \& Martínez Prats, Germán. (2021). Mecanismos alternativos en la solución de conflictos para la construcción de una cultura de paz. Ciencias de la documentación, 7(1), 15-23.

7. Hutchinson, Tomás. (2004). El proceso de ejecución de sentencias contra el Estado. Revista Latinoamericana de Derecho, 1(1), 289-355.

8. Naime González, Alejandro \& Zaragoza Contreras, Laura G. (2019). El principio de igualdad en el Procedimiento Abreviado. Derecho y Cambio Social, (58), 360- 385.

9. Organización de los Estados Americanos. (1969). Convención Americana sobre Derechos Humanos. Departamento de Derecho Internacional, Secretaría de Asuntos Jurídicos: Costa Rica.

10. Silva-Hernández, Francisca. (2020). Hacia una comprensión del conflicto en justicia alternativa. Revista de Investigaciones Universidad del Quindío, 32(1), 61-65. https://doi.org/10.33975/riuq. vol32n1.435

11. Tribunal Europeo de Derechos Humanos. (2011). Caso Saleck Bardi contra España. Sentencia de 24 mayo 2011 JUR 2011\174772. Francia. 